\title{
The design of multi-function KIT - MULTIBOARDTNUT used at the laboratory of Thai Nguyen University of Technology
}

\author{
Duy Khanh Pham, Van Nam Bach
}

\begin{abstract}
This project introduces a design of multi board software development KIT, which can be used to practise programming for many different processors, microcontrollers, embedded computers. The project supports for courses, such as, board design, embedded system, digital integrated circuit design, microprocessor - micro controller, at Faculty of Electronic Engineering, Thai Nguyen University of Technology.
\end{abstract}

Index Terms - multi board, processors, microcontrollers, embedded computers

\section{INTRODUCTION}

Now, there are many hardware and software providers offering families of digital ICs and embedded computers. Using these ICs and embedded computers facilitates the design a variety of systems, such as: Smart home, fire alarm control, or temperature control for brooder heater ... Together with the development of digital ICs and embedded systems, manyfactures has designed a lot of versions of software development KIT, which provide the application programming interfaces for studying programming languages. For example, The 8051 Lab Trainer KIT [1] for 8051 microcontroller, Educational Practice Board for AVR Atmega32 [2], or Elegoo EL-KIT-001 UNO R3 [3] for Arduino... These software development KIT includes a series of I/O devices, like: Single LED, 7-segment LED, LCD display, buttons, sensors ... which are fixedly connected with the pins of digital ICs or embedded computers. For this reason, if we want to work with different types of IC, we need to buy different types of KIT. The purpose of this research is to design a multiboard software development KIT, which can connect with some different types of microcontrollers and microprocessors, or embedded computer, through a set of board connectors, to become the experimental tools for some courses.

\section{THE BLOCK DIAGRAM OF KIT}

In order to carry out the design of a versatile test KIT that can be used for a variety of microprocessors, microcontrollers, to purchase different KITs, the team developed the block diagrams of MULTIBOARDTNUT are shown in the Figure 1.

Duy Khanh Pham, Department of Electronics Engineering, Thai Nguyen University of Technology, Thai Nguyen, Vietnam, +84972992282

Van Nam Bach, Department of Electronics Engineering, Thai Nguyen University of Technology, Thai Nguyen, Vietnam, +84936665822

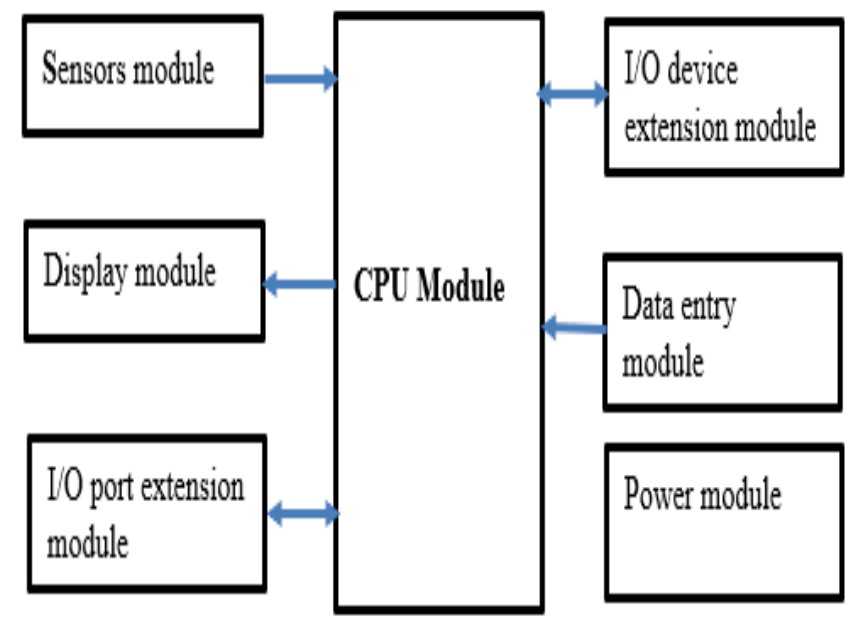

Fig. 1: The block diagram of KIT

The function of all the blocks in the diagram:

- Sensors module: Included some type of sensors, such as, temperature sensors (18B20, LM35), humidity sensor (DHT11), gas sensor (MQ2), fingerprint sensor, dedicated to sensor reading experiment.

- Display module: Included many single LEDs, 7-segment LEDs, LCD $128 * 64$, LED matrix $8 * 8 \ldots$ support for parametters display, of blinking LED experiments.

I/O port extension module: This module is used to extend the input or output port for the ICs, embedded computer in some specific applications.

- Data entry module: Included buttons, keyboard, for importing all the input data, parameters ...

I/O device extension module: For connecting the external I/O devices which are not integrated on the KIT.

- CPU module: is connected with the board through two row of board connectors, these two row are already linked to all the block on the KIT. If the users use the KIT with any microprocessors, microcontrollers, or embedded systems, they can themselves design the connector panel or directly connect with the I/O devices through the wires.

\section{THE PRINTED CIRCUIT DESIGN FOR KIT}

To design the circuit for the KIT, we use the Altium Designer software for creating both schematic and printed circuit drawing for the KIT (Figure 2). 
The design of multi-function KIT - MULTIBOARDTNUT used at the laboratory of Thai Nguyen University of Technology

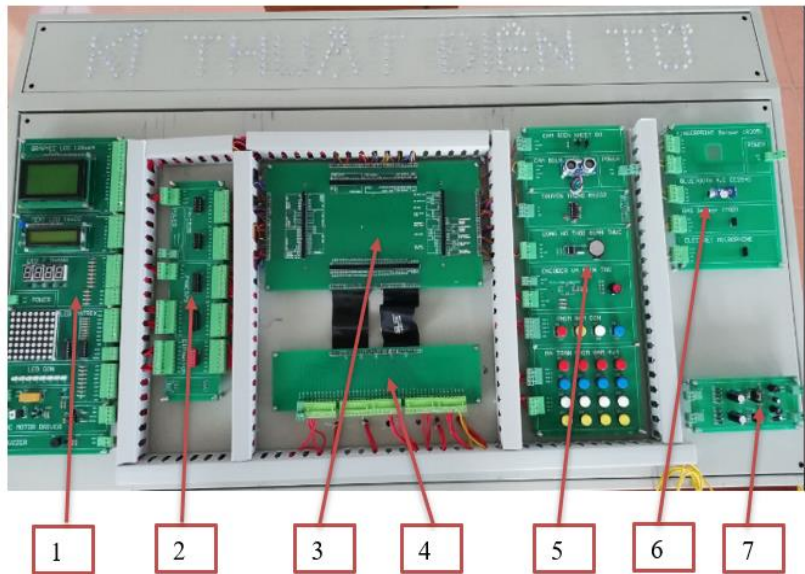

Fig. 2: Picture of MULTIBOARDTNUT KIT

\subsection{Printed circuit for Display module}

Printed circuit for Display module (Block 1 - Figure 2) includes $128 * 64$ LCD display, 16*2 LCD display, single LED, 7-segment LED, and LED matrix. This module is connected with the CPU through Connecter EDG (Block 4 Figure 2).

\subsection{Printed circuit for sensors module}

Printed circuit for sensors module (Block 5 - Figure 2) includes temperature, hudimidity, distance, fingerprint, gas sensors, bluetooth module, electret microphone. This module is connected with the CPU through Connecter EDG (Block 4 - Figure 2).

\subsection{Printed circuit for $\mathrm{I} / \mathrm{O}$ port extension module}

Printed circuit for I/O port extension module (Block 2 - Figure 2) includes IC 74HC595, IC 74HC573 and DIP Switch. This module is connected with the CPU through Connecter EDG (Block 4 - Figure 2).

\subsection{Printed circuit for power supply module}

Printed circuit for power supply module (Block 7 Figure 2). This module supplies electric power to all the blocks. The power supply provide the $+5 \mathrm{~V},+3.3 \mathrm{~V}$, GND voltage.

\subsection{Printed circuit for CPU module}

Printed circuit for CPU module (Block 3 - Figure 2) links to all blocks of the KIT. This module is integrated rows of female board connector, to practise programming with KIT, user will connect the microprocessor, microcontroller, of embedded computer with the I/O devices through these rows of female board connector.

\section{DESGIN OF SOME CPU MODULE CIRCUIT}

To evaluate the performance of the KIT and make the experimental manual for the courses, we design some CPU modules, including: CPU module using Arduino Mega (Figure 3, Figure 4), CPU module using PIC 16F887 (Figure 5, Figure 6), CPU module using Raspberry Pi 3 (Figure 7). These CPU modules are designed for some experiment exercises as follow: Program to read value of temperature, hudimidity sensors and display on LCD $128 * 64$ and LCD 16 *2, Program for running text " KỸ THUẬT ĐIỆN TỦ" with LED, and Program to display the value of distance on LCD $128 * 64$ and LCD 16*2.

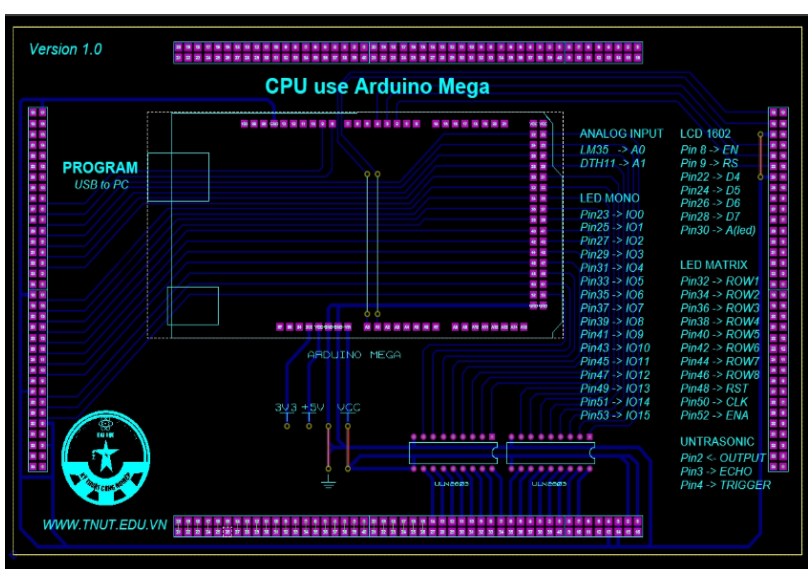

Figure 3: Printed circuit image of the central processing module using the Arduino

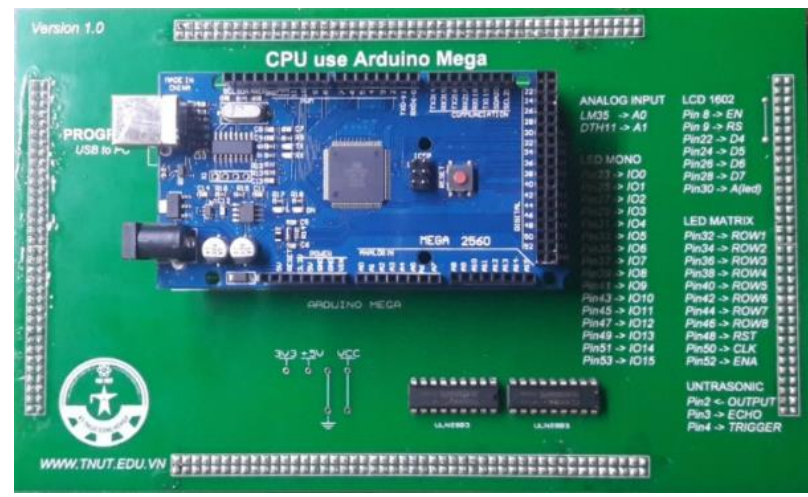

Figure 4: Real circuit image of the central processing module using the Arduino Mega

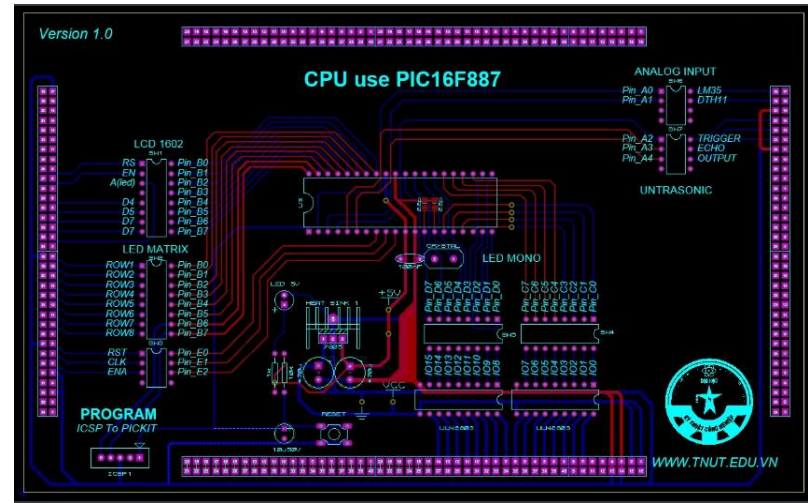

Figure 5: Printed circuit image of the central processing module using PIC16F887

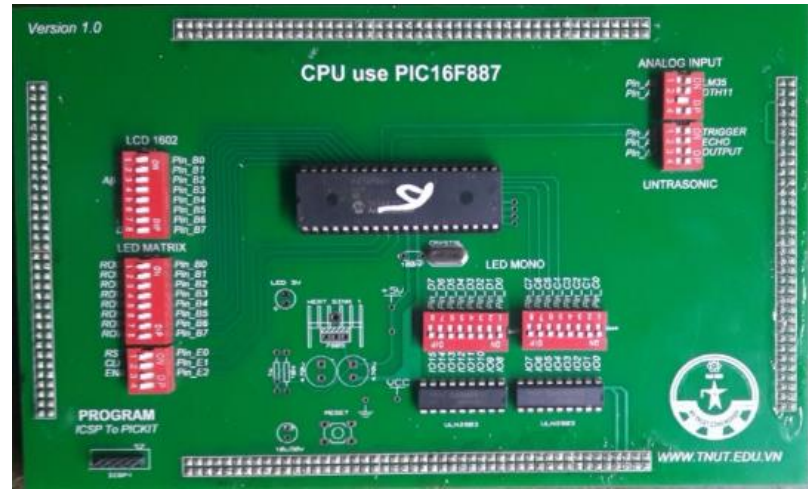

Figure 6: Real circuit image of the central processing module using PIC16F887 


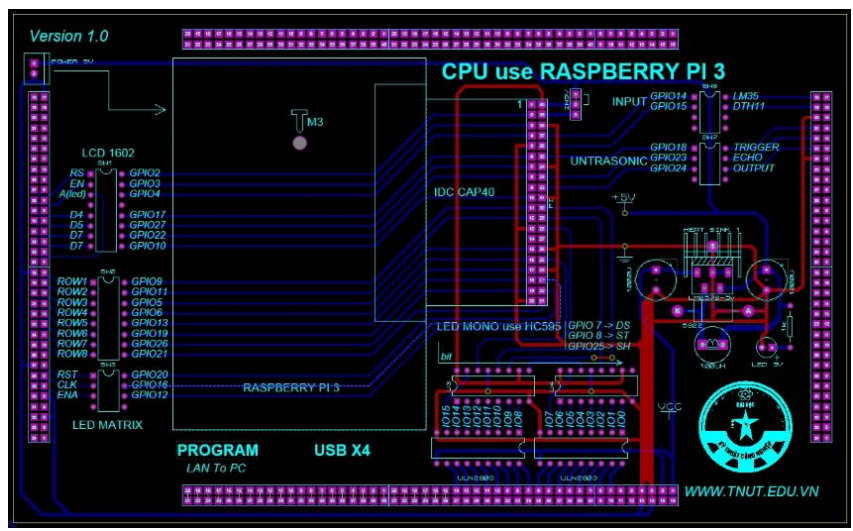

Figure 7: Printed circuit image of the central processing module using Raspberry Pi 3

\section{CONCLUSION}

This project proposed an idea of designing a multiboard software development KIT which can connect with many of I/O devices, using many different types of microprocessors, microcontrollers, and embedded computers. This project also provides the design of some CPU modules with many different types of microprocessors, microcontrollers, and embedded computers and detailed experiment manuals as the reference material for some courses in electronic engineering field. The result of the project will be used at the Electronic Engineering Laboratory, Faculty of Electronic Engineering, Thai Nguyen University of Technology.

\section{ACKNOWLEDGMENT}

This research was supported by a grant for the university research from the TNUT (Thai Nguyen University of Technology), under project T2018-TN05. We thank our colleagues from the TNUT who provided insightand expertise that greatly assisted the research.

\section{REFERENCES}

[1]. https://www.pantechsolutions.net/8051-lab-trainer-kit.

[2]. https://www.edutechlearning.com/learningresoursedesc/electronics-e ngineering/cpu-target-boards/educational-practice-board-for-avr-atmega32. [3]. https://www.amazon.com/Elegoo-EL-KIT-001-Project-Complete-Tu torial/dp/B01CZTLHGE.

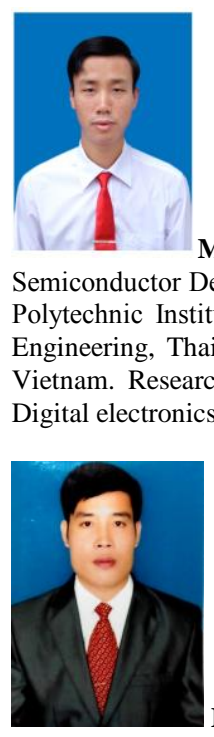

MSc Duy Khanh Pham is master in Microelectronics and Semiconductor Devices at National Technical University of Ukraine "Kiey Polytechnic Institute", Ukraine. He is working at Faculty of Electronics Engineering, Thai Nguyen University of Technology, Thai Nguyen City, Vietnam. Research interests: Semiconductor materials, Analog electronics, Digital electronics, Biomedical electronics.

MSc Van Nam Bach is master in Electronic engineering at Thai Nguyen University of Technology, Viet Nam. He is working at Faculty of Electronics Engineering, Thai Nguyen University of Technology, Thai Nguyen City, Vietnam. Research interests: Analog electronics, Digital electronics, Design Printed Circuit Board. 